This item was submitted to Loughborough's Research Repository by the author.

Items in Figshare are protected by copyright, with all rights reserved, unless otherwise indicated.

\title{
Bipedal humanoid robot that makes humans laugh with use of the method of comedy and affects their psychological state actively
}

PLEASE CITE THE PUBLISHED VERSION

http://dx.doi.org/10.1109/ICRA.2014.6907119

PUBLISHER

(C) IEEE

VERSION

AM (Accepted Manuscript)

LICENCE

CC BY-NC-ND 4.0

\section{REPOSITORY RECORD}

Kishi, Tatsuhiro, Nobutsuna Endo, Takayuki Nozawa, T. Otani, Sarah Cosentino, Massimiliano Zecca, Kenji Hashimoto, and Atsuo Takanishi. 2019. "Bipedal Humanoid Robot That Makes Humans Laugh with Use of the Method of Comedy and Affects Their Psychological State Actively". figshare.

https://hdl.handle.net/2134/17595. 


\title{
Bipedal humanoid robot that makes humans laugh with use of the method of comedy and affects their psychological state actively
}

\author{
T. Kishi, N. Endo, T. Nozawa, T. Otani, S. Cosentino, M. Zecca, K. Hashimoto and A. Takanishi, \\ Member, IEEE
}

\begin{abstract}
This paper describes the bipedal humanoid robot that makes human laugh with its whole body expression and affect human's psychological state. In order to realize "Social interaction" between human and robot, the robot has to affect human's psychological state actively. We focused on "laugh" because it can be thought as a typical example for researching "Social interaction". Looking through a Japanese comedy style called "manzai" or the art of conversation, we picked out several methods for making human laugh. Then we made several skits with the advice of comedians, and made the whole body humanoid robot perform them. Results of experimental evaluation with these skits shows that the robot's behavior made subjects laugh and change their psychological state seen as a decrease of "Depression" and "Anger".
\end{abstract}

\section{INTRODUCTION}

$\mathrm{I}_{\mathrm{c}}^{\mathrm{n}}$ an aging society, there is a growing need for a robot that can perform not only the alternative way of labor but also support human's daily life including medical treatment(?) and nursing. These robots should communicate with humans naturally in order to support them both physically and psychologically.

When a human communicates with another fluently, there is an interaction called "Social interaction" in psychology or social science. That means humans communicate with each other assuming the other's psychological state include emotion or mood watching their behavior and change his or her behavior thinking about how the other will react to it or how it will change the other's psychological state[1]. In this way, humans assume each other's psychological state and change it actively. If this kind of interaction was to be realized between a robot and a human, the robot could support human life more naturally assuming human's sadness mood and behaving in order to change it to a positive mood.

This study was conducted with the support of the Research Institute for Science and Engineering, Waseda University and as part of the humanoid project at the Humanoid Robotics Institute, Waseda University. It was also supported in part by the MEXT/JSPS KAKENHI Grant No. 25220005; Global COE Program "Global Robot Academia", MEXT, Japan;) Grants for Excellent Graduate Schools, MEXT, Japan; we thank all of them for the financial and technical support provided.

T. Kishi is with the Graduate School of Science and Engineering, Waseda University, \#41-304, 17 Kikui-cho, Shinjuku-ku, Tokyo 162-0044, JAPAN (e-mail: contact@takanishi.mech.waseda.ac.jp) and also a research fellow at the Japan Society for the Promotion of Science.

N. Endo is with the Graduate School of Engineering, Osaka University.

T. Nozawa is with the Faculty of Human Studies, Mejiro University.

T. Otani, S. Cosentino and M. Zecca are with the Graduate School of Science and Engineering, Waseda University.

K. Hashimoto is with the Research Institute for Science and Engineering, Waseda University.

A. Takanishi is with the Department of Modern Mechanical Engineering, Waseda University; and one of the core members of the Humanoid Robotics Institute (HRI), Waseda University.
Focusing on the robot's side, in order to realize the "Social interaction" with humans, robots should have four functions presented below(Fig. 1).

- Assume human's psychological state from their behavior

- Change robot's psychological state according to external stimuli

- Express robot's psychological state

- Affect human's psychological state

There are many researches about robots that aim to realize the communication with human. For example, Okao-vision can assume human's psychological state from their facial expression[2]. Leonard[3] or WE-4RII[4] have virtual psychological states and can react to the external stimuli. Geminoid[5] or HRP-4C[6] have human-like appearance for expressing human-like messages. But there are less approaches that aim to affect human's psychological state with active behavior of robot. Paro[7] was developed in order to commit human's mental state, but it can only react to the human's affection in passive ways.

We have also been developing a whole body humanoid robot that can interact with humans. In 2007, we have developed KOBIAN-R[8,9] that can react to the external stimuli with its virtual model of psychological state and express its psychological state with its whole body and moving around.

This research is focused on making humans laugh in order to affect human's psychological state actively. In this paper, especially we describe the way we tried to make humans laugh and the method and results of the experiment in order to examine if the robot can change human's psychological state with its behavior. First, we searched for the methods to make humans laugh from a method of comedy, "manzai" or the art of conversation. Then we made KOBIAN to perform the skits with its whole body based on these methods to make humans laugh thanks to the advice of comedians. The result

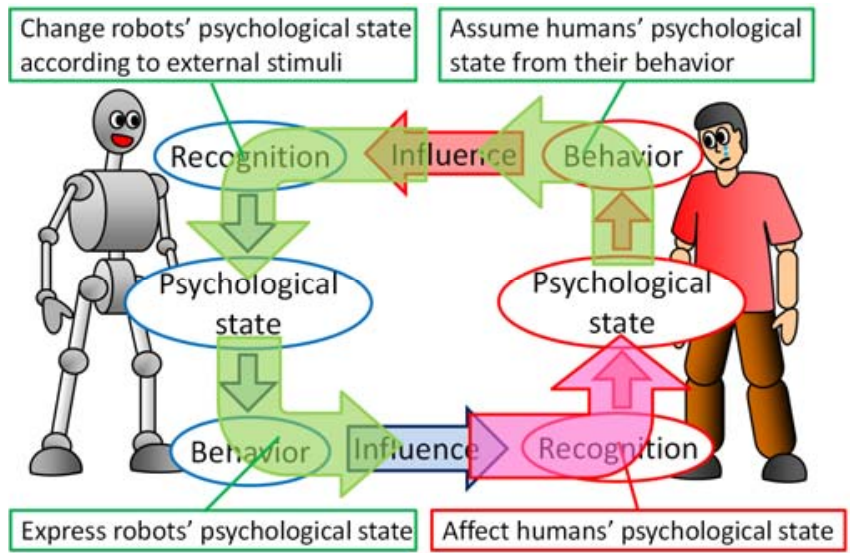

Fig. 1. Social Interaction between a human and a robot. 
of the evaluation showed that our robot could make humans laugh and it affected their psychological state.

In this paper, Chapter II shows the way to define the behavior of the robot in order to make humans laugh. The content of the skits with the robot's performance is shown in Chapter III. The method and results of experimental evaluation are described in Chapter IV. Finally, the paper concludes and the future works are described in Chapter V.

\section{HOW TO MAKE HUMAN LAUGH WITH ROBOT'S WHOLE BODY EXPRESSION}

\section{A. Interaction through laughter}

Many ways could be thought for the robot to change human's psychological state during interaction, but in this research we choose making humans laugh. That's because firstly laugh is an involuntary movement and can be detected by physiological measurements. For example, we achieved to detect subject's laugh from the movement of diaphragm using an EMG sensor and an acceleration sensor [10]. That means that reactions to the robot's affect can be easily detected. Secondly, previous research shows that when a human laughs, his or her mood changes to positive. That means if a robot can make a human laugh, it might affect its psychological state. Third, we can see "infectious laugh" during the interaction between humans. Infectious laugh is said to be caused because when one person sees another laugh, he or she assumes the other person's positive mood and his mood is brought to positive and laughs. So we can say that Infectious laugh is a typical example for social interaction. Supported by these reasons, we focused on laughter as a good example of research of interaction between a human and a robot.

From now on, there are some examples of robots that make humans laugh. For example, comedy is realized by comic duo between two Robovie[11], Papero and Zen-jiro[12], and ii-1 and ii-2[13]. The purpose of these researches are not to achieve interaction between humans and a robot but to make human laugh itself. So the interaction is closed between the performers. These researches also didn't conduct any experiment in order to examine how these robots' behavior affect humans' psychological state.

In addition, human comedians perform comedy with moving their whole body fast and wide and changing facial expressions for making human laugh effectively. However the robots used in the previous researchs are all wheeled small robots. Therefore, almost all of their skits consisted of funny talks and did not include motions of their body.

Considering these aspects, we decided the purpose of this research to be to achieve a biped humanoid robot that can affect humans' psychological state actively through making them laugh with its whole body expression.

\section{B. Research about laugh}

In psychology and social science, there are many researches about the mechanism how humans recognize the humor. Theory by Suls[14] suggests that the humor is recognized from the gap between predictions and reality. In addition, the mechanism how the gap produces the laugh is shown in the Spencer and Floit theory by Y. Kimura[15]. This theory says that when a human is highly stressed and suddenly the stress is released, he or she laughs.

Many ways of performances for making humans laugh as comic story, comedy, gag, joke, comic drama have been created. All of these are based on the strategy to create the gap between predictions and reality. In order to achieve skits for robots to make humans laugh, the creation of the gap is also thought to be important. So we studied the way these performances produce this kind of gap.

\section{Methods for making humans laugh}

Part of the methods for making humans laugh are published by comedians or researchers. In order to achieve a robot's behavior for making humans laugh based on these methods, we studied 6 books[16-21] in which the methods for comedy, "manzai" and the ways for funny conversations are gathered comprehensively. These methods in the books are picked up from wide range of skits or ways of expressions, but most of the methods are commonly the same between other contents. We extracted the methods that are especially common in these books and show them below.

\section{1) Funny behavior \\ - Overblown: Exaggerate too much \\ - Equivoque: Homonym or parody \\ - Blue jokes: Make a dirty joke}

- Sympathetic story: Saying the empathic small things that almost everyone has experienced once

- Induced laugh: Comedian laughs aimed to the audiences' infectious laugh

\section{2) Funny context}

- Running gag: Use the same story again and again

- Unexpected: Do completely unexpected behavior

\section{3) Funny character \\ - Self-flattery, Self-deprecating humor \\ - Imitation}

\section{Making skits}

Based on these methods, we made the skits performed by KOBIAN with its whole body expression. In making the details of the patter or motion, we discussed with comedians. Until now, most of the researched robots performed funny skits by the style like "manzai" duo. In this case, interaction is closed between the performer. However, concerning about future extensions for interaction between humans, we selected the skits that can be performed by one robot. We made 12 skits and the length of them were from 20 second to three minutes. These skits are achieved by the combination of the methods we showed before. In order to make a wide range of humans laugh, we made the skits with as many methods as possible (Table 1).

\section{SKITS PERFORMED BY KOBIAN}

The typical example of skits are described below. The methods used in each skit are shown in $<>$. The motion and patter during those skits are shown in Tables 2 to 7 . 


\section{A. Opening greeting (Table 2)}

KOBIAN bows deeply and says "Hello, I'm KOBIAN". It strikes a pose rubbing its hand and says "I'm KOBIAN because I always flatter humans". In Japanese, "flatter" is pronounced as "KOBI-ru", so this is an <equivoque> sentence. Then it says "Hi! boss, let's go drinking" and KOBIAN < unexpectedly > invite human to drinking although it is a robot. Next it says "I can't drink alcohol because I am a robot" using its identity with <sympathetic story> method. Finally it orders oil as the normal robot saying "Excuse me, please give me a cup of oil" as the <self-deprecating> method.

\section{B. No surprise exercise (Table 3)}

This skit is performed by the <imitation> of Japanese famous comedian named COWCOW. This skit is consisted of the parody of the a content where a young man dances to the music for teaching exercises for children in a TV show. Such kind of TV show is very popular in Japan. The funninest of this comedy is that some natural things are explained as if they were an unusual thing in an <overblown $>$ way.

In the beginning of this skit, KOBIAN puts his hand on its waist and tilts forward a bit saying "Hi everyone, it's time for "No surprise exercise!". Let's start!". After that the music starts and KOBIAN begins a bending and stretching exercise to the words "No surprise! No surprise! No surprise exercise!"

Then KOBIAN starts walking to the words "Move your right leg forward, then your left leg forward, then..." and when the words continuing "You can walk!", KOBIAN turn to the front and strikes a pose with a smile. The words "No surprise! No surprise! No surprise exercise!" stream again. This is the $<$ running gag $>$ method.

In the same way, KOBIAN performs to the words that says only natural things "When you play "Rock, paper, scissors" and you decide which one to show after seeing the others' hands, you can win!", "If you strike other's knee from back, the knee bends!" and "A, I, U, E, O, KA, KI, KU, KEKO! (Japanese alphabet)" striking a pose with a facial expression again and again. The sound of this skit is supplied from the original skit by COWCOW.

\section{Imitation of Kein Kosugi (Table 4)}

This skit is an <imitation> of an American actor famous in Japan who's way of speaking is characteristic. This actor is famous for his well-muscled body, this skit uses this characteristic.

In the beginning, KOBIAN says "The next skit is the imitation of Kein Kosugi who's Japanese is not fluent but his Engish is fluent." It is one of the commonly used way where the comedian explains its story beforehand. It aims to make the audience assume the robot's behavior in order to clarify the gap of the skit. After that KOBIAN point to its body parts saying "Ah...Fukkin (abdominal muscle)", "Ah...Kyoukin(breast muscle)" and "Ah...Jyouwankin(brachial muscle)" with not fluent Japanese. This is an <overblown $><$ imitation $>$ of the way of speaking of Kein Kosugi. Then KOBIAN continues in the same way of saying "Subete kita-e-re-ba, ki-mi-mo... (If you train them all, You also will have the...)". Then KOBIAN says with perfect English "Perfect body!". The < unexpected $>$ changing of the tone and way of saying produces the gap and that makes funniness. Finally KOBIAN says "Isn't it good? The voice is just like as the original!". Robot can record and play every voice, so it is the use of <sympathetic story $>$ method. The voice in this skit is the voice of the Japanese comedian Takahiro Yamamoto.

\section{D.Imitation of Masuo-san (Table 5)}

"Masuo-san" is a very famous character of a Japanese cartoon named "Sazae-san". First KOBIAN explains the skit saying "Next skit is the imitation of a surprised Masuo-san from the cartoon "Sazae-san"'. It aims that audience's expectation of story produces the gap clearly. Then it makes $<$ overblown $><$ imitation $>$ of body pose and facial expression saying "Ee!" in <unexpectedly> loud voice. The tone of the voice and posture produces the gap. Then it repeats the pose and voice "Ee!" "Ee!" "Ee!" as the <running gag> method. The voice of "Ee!" is the voice in comedy by CANxCAN.

\section{E. KOBIAN laughs (Table 6)}

KOBIAN laughs a lot which aims $<$ infectious laugh $>$ of the communication partner.

Table.1 Use of method of comedy

\begin{tabular}{|c|c|c|c|c|c|c|c|c|c|c|}
\hline \multirow[b]{2}{*}{ Title } & \multicolumn{5}{|c|}{ Behavior } & \multicolumn{2}{|c|}{ Context } & \multicolumn{3}{|c|}{ Character } \\
\hline & Overblown & Equivoque & $\begin{array}{l}\text { Blue } \\
\text { jokes }\end{array}$ & $\begin{array}{c}\text { Sympathetic } \\
\text { story }\end{array}$ & $\begin{array}{c}\text { Infectious } \\
\text { laugh }\end{array}$ & \begin{tabular}{|c|} 
Running \\
gag
\end{tabular} & Unexpected & $\begin{array}{c}\text { Self } \\
\text { deprecating }\end{array}$ & $\begin{array}{c}\text { Self- } \\
\text { flattery }\end{array}$ & Imitation \\
\hline Opening greeting & & $\mathrm{O}$ & & & & & $\mathrm{O}$ & $\mathrm{O}$ & & \\
\hline Imitation of Masuo-san & $\mathrm{O}$ & & & & & $\mathrm{O}$ & $\mathrm{O}$ & & & $\mathrm{O}$ \\
\hline No surprise exercise & & & & $\mathrm{O}$ & & $\mathrm{O}$ & & & & $\mathrm{O}$ \\
\hline Imitation of Kein Kosugi & O & & & & & $\mathrm{O}$ & $\mathrm{O}$ & & & $\mathrm{O}$ \\
\hline Funny face & & & & $\mathrm{O}$ & & & $\mathrm{O}$ & $\mathrm{O}$ & $\mathrm{O}$ & \\
\hline KOBIAN laughs & & & & & $\mathrm{O}$ & & & & & \\
\hline Scared robot & $\mathrm{O}$ & & & & & & $\mathrm{O}$ & & & \\
\hline Shoulder discomfort of robot & & & & $\mathrm{O}$ & & & & $\mathrm{O}$ & & \\
\hline Robot dance & & $\mathrm{O}$ & & & & & & $\mathrm{O}$ & & \\
\hline Spew venom & & & & & & $\mathrm{O}$ & $\mathrm{O}$ & & $\mathrm{O}$ & \\
\hline Transform & & & & $\mathrm{O}$ & & & $\mathrm{O}$ & $\mathrm{O}$ & & \\
\hline Ending greeting & & & $\mathrm{O}$ & $\mathrm{O}$ & & & $\mathrm{O}$ & & & \\
\hline
\end{tabular}


Table2 Opening greeting

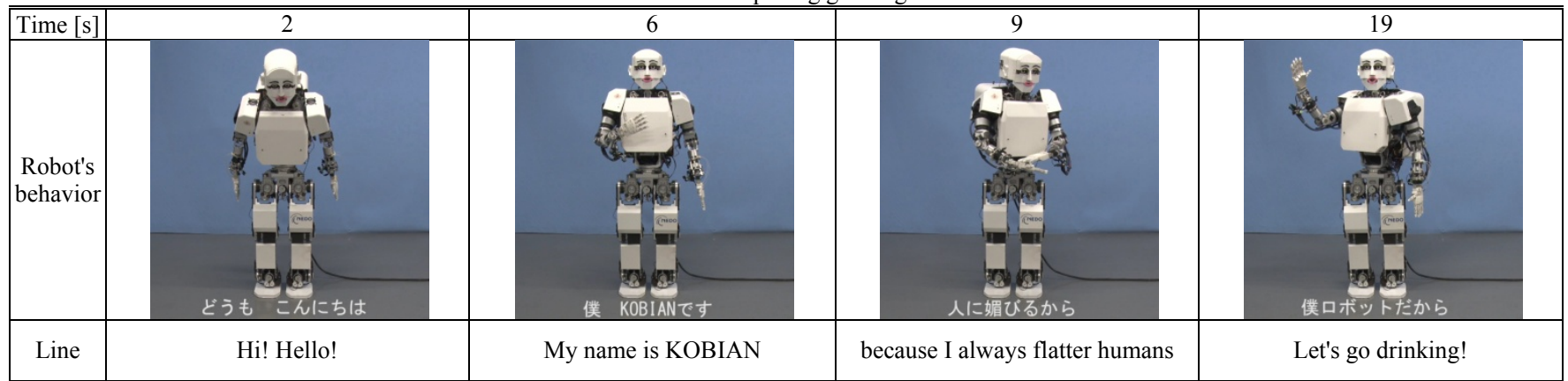

Table 3 No surprise exercise

\begin{tabular}{|c|c|c|c|c|}
\hline \hline Time [s] & 2 & 23 \\
\hline $\begin{array}{c}\text { Robot's } \\
\text { behavior }\end{array}$ & 当たり前体操の時間たよ〜 & No surprise...No surprise...No \\
surprise exercise! & $\begin{array}{c}\text { Move your right leg forward, then } \\
\text { your left forward to... }\end{array}$ \\
\hline
\end{tabular}

Table 4 Imitation of Kein Kosugi

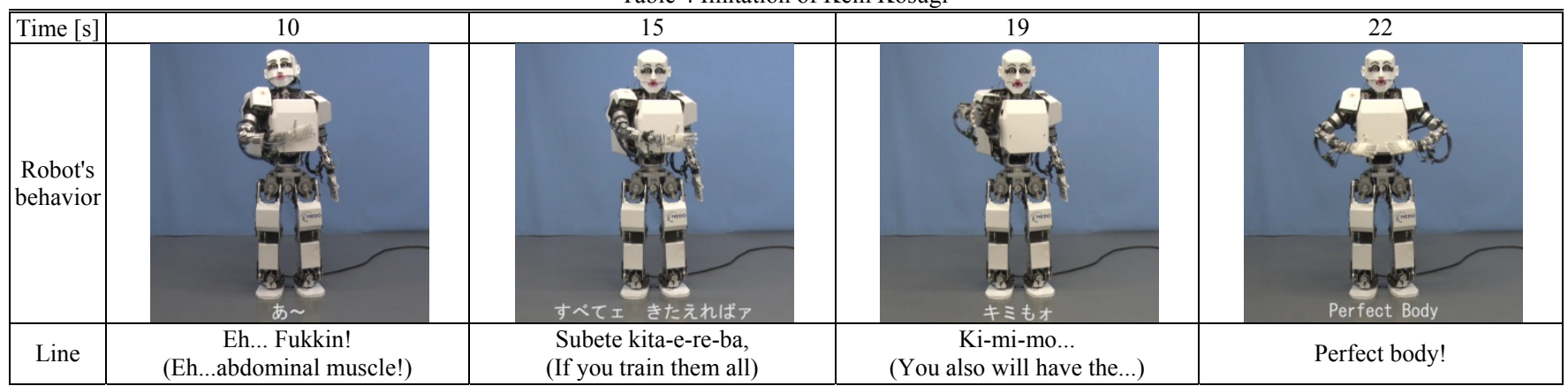
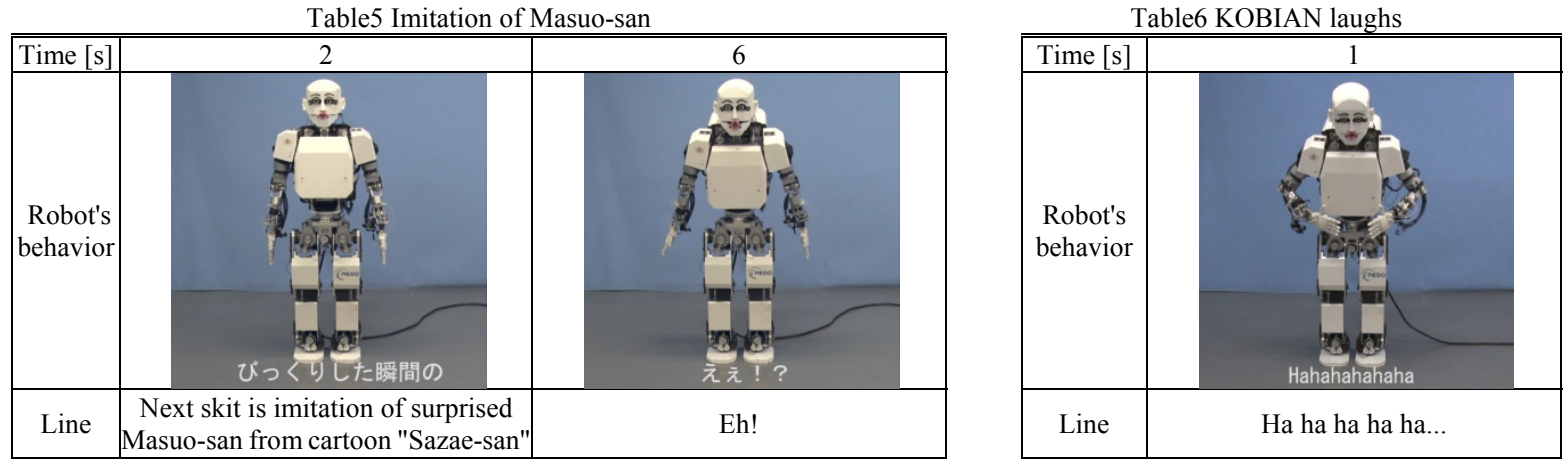

Table7 Ending greeting

\begin{tabular}{|c|c|c|c|c|}
\hline \hline Time [s] & 3 & & \\
\hline $\begin{array}{l}\text { Robot's } \\
\text { behavior }\end{array}$ & Oops! It's time to go. & $\begin{array}{c}\text { It's not a case to say such a thing. } \\
\text { I have no time! }\end{array}$ & Thank you. KOBIAN speaks. \\
\hline Line & KOBIANでした & KOMANECHI! \\
\hline
\end{tabular}




\section{F. Ending greeting (Table 7)}

First KOBIAN says "Oops! It's time to go". "I should go to the part-time work in the convenience store as I am a robot." Robots doing a part-time work is thought to be quite usual, so it is use of $<$ Sympathetic story $>$ method. KOBIAN feed its own lines saying "I have no time to say such a thing. I have no time!" and KOBIAN strikes a pose to hit someone just as "manzai" performers do. Finally KOBIAN greets saying "Thank you. KOBIAN speaks." and $<$ Unexpectedly $>$ strikes a pose of KOMANECHI (exaggerate expression of high-cut swimsuit) with use of $<$ Blue jokes $>$ method saying "KOMANECHI!"

\section{EXPERIMENTAL EVALUATION}

We conducted an experiment in order to evaluate if the skits by the robot can make humans laugh, and can affect humans' psychological state. We recorded the stories in video and showed them to 21 subjects (19 men and 2 women) who joined the experiment and whose average age was 23.2. As the previous research about laugh shows if there is more than one subject in the experimental space, infectious laugh occurrs between the subjects[22]. This phenomenon prevents us to examine the reason why the subjects laugh. So we conducted the experiment one by one subjects in a closed space. All the skits were recorded on separated videos. The order of the skits we showed them s were as below. First, "Opening greeting" was shown. Finally "Ending greeting"

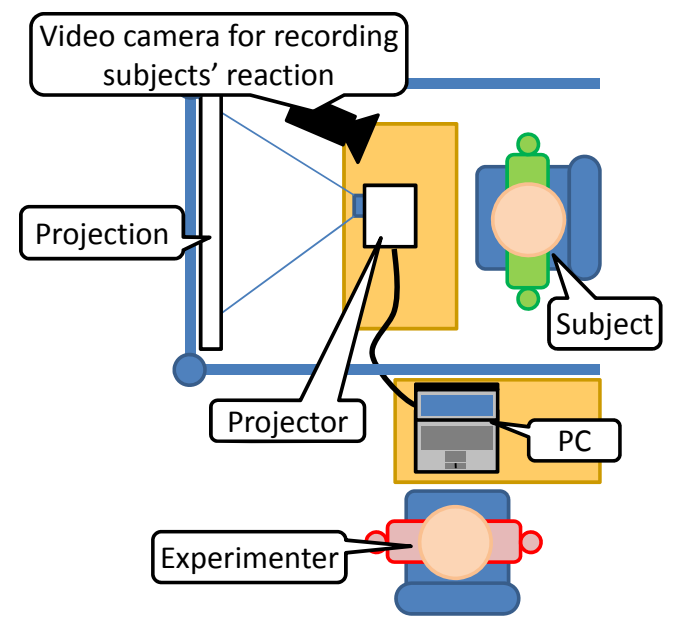

Fig. 2. Experimental setup

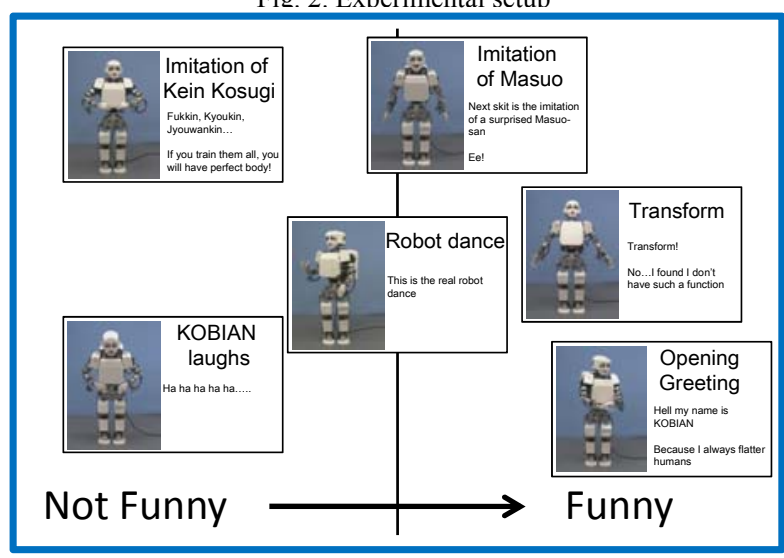

Fig. 3. Subjective evaluation of funniness with the board was shown. Between them, all the other videos were shown in random order. In order to achieve the effect of "Infectious laugh," the skit "KOBIAN laughs" was inserted between every other videos. The full length of the experiment was about 10 minutes.

We evaluated the stories in three ways. First, we recorded the subjects' reaction with a video camera and analyzed it. Second, in order to evaluate if the robot's story could affect subjects' psychological state, we conducted a questionnaire to check their mood with the method called POMS(Profile of Mood States) [23] before and after showing the video and compared the differences. Finally, we evaluated the subjective funniness of each story with a board on which subjects attached the plate of the stories depending on the funniness they felt(Fig. 3). The results are shown below.

\section{A. Reaction analysis}

In order to analyze the subjects' reaction, we categorized the reaction as below. If the subjects burst into laugh, we categorized it as "Laugh" and if the subjects change their facial expression from "Neutral" to "Smile" and didn't burst into laugh, we categorized it as "Smile." Fig.4 shows an example. The result is shown in Fig. 5. This result shows that especially "Imitation of Masuo-san", "No surprise exercise" and "Opening greetings" made more than half subjects laugh.

\section{B. Result of POMS and change of subject's psychological state}

The result of comparison of the POMS results between, before and after showing videos is shown in Fig. 6 . "Depression" and "Anger" were significantly decreased. This is thought to be because the subjects' laugh changed their mood to positive as psychologists' suggest. This results shows that the robot achieved to affect human's psychological state with its behavior.

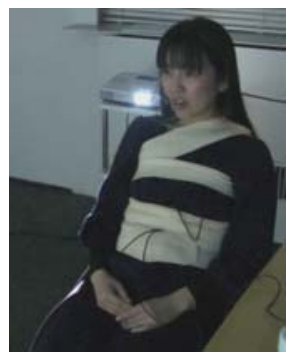

(a) Neutral

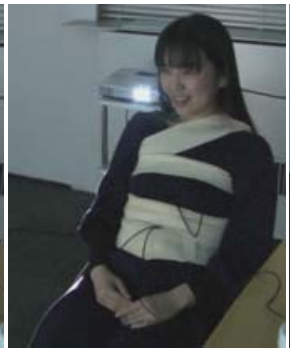

(b)Smile

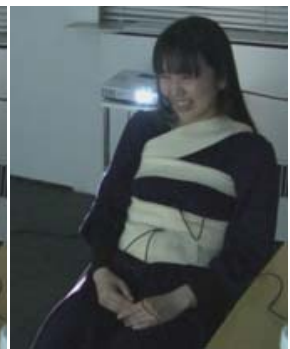

(c)Laugh

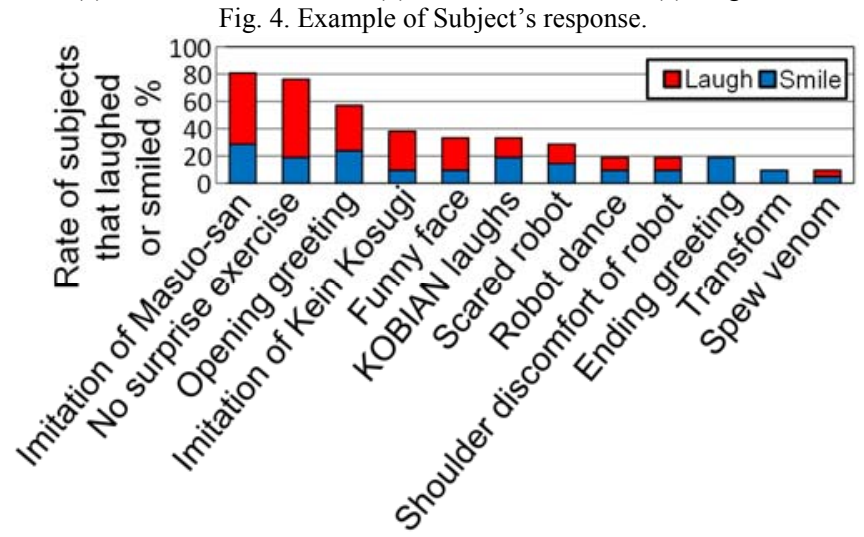

Fig. 5. Subjects' reaction 


\section{Evaluation of subjective funniness}

We calculated the subjective funniness based on where on the board the subjects attached every plate that described the stories. We calculated the subjective funniness of every stories defining the left side of the board is 0 points and the right side is 100 points. Fig. 7 shows the results. Comparison of this result and results about subjects' laugh shows that in most stories, the tendency of the order of number of the subjects whom the story made laugh and value of subjective funniness was the same.

However, though "Imitation of Kein Kosugi" made four times more subjects laught than "Spew venom," its subjective funniness was lower. That means a different cause from funniness made subjects laugh. One of the causes could be the difference of the impression caused by robot's whole body expression including facial expression. In "Imitation of Kein Kosugi", the movement of body parts and facial expression are very wide. On the other hand, "Spew venom" was the skit in which KOBIAN only tells the funny story, the movement of body parts and facial expression were small and impression was less dynamic. This result has a possibility to suggest that in order to make humans laugh with robot's motion, dynamic expression with body and facial expression is effective.

In addition, though "KOBIAN laughs" made many subjects laugh, the value of subjective funniness of this skit was low. That might suggest that subjects didn't laugh because of the funniness of the story but because of the effect of infectious laugh. That might show the effectiveness of the robot to laugh itself in order to make human laugh by infectious laugh effect.

\section{V.CONCLUSION AND FUTURE WORKS}

In order to achieve an interaction between humans and robots that includes the robot's active affection to the human's

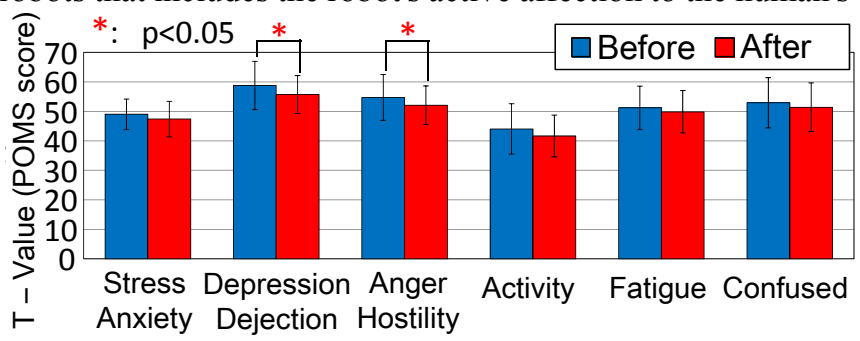

Fig. 6. Result of POMS that shows the affection of subjects' psychological state

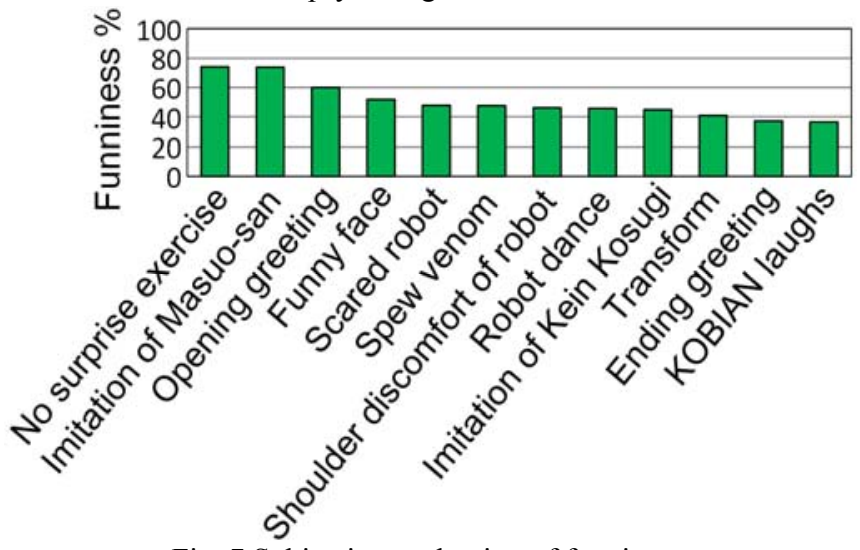

Fig. 7 Subjective evaluation of funniness psychological state, we conducted an experiment of making humans laugh with robot's behavior. We achieved robot's skits with robot's whole body expression based on the combination of methods of making human laugh. The result by video of robot's comedy shows that the robot realized to make human laugh. The results also suggested that when a robot makes human laugh, its whole body expression including its facial expression might be effective. It is also suggested that when robot laughs, infectious laugh could occur between robot and human. Through making human laugh, robot's behavior affect humans' psychological state seen in the slight decrease of "Depression" and "Anger".

In the future, we are planning to make more skits and conduct an experiment with more subjects in order to examine the relationship between reaction and combination of methods of comedy. In addition, we are planning to examine the effect of embodiment of the robot to the reaction of the subjects, and to feedback the humans' laugh reaction to the robot to achieve the interaction between a robot and a human through laughing.

\section{REFERENCES}

[1] Y. Nakajima et.al: "Psychological dictionary", Yuuikaku, 1999.

[2] "OKAO Vision" http://www.omron.co.jp/ecb/products/mobile/

[3] A. Thomaz et. al: "An Embodied Computational Model of Social Referencing", Robot and Human Interactive Communication, 2005

[4] K. Itoh, et al., "Mechanical Design of Emotion Expression Humanoid Robot WE-4RII" Proc. of 16th CISM-IFToMM Symposium on Robot Design, Dynamics and Control, pp. 255-262, 2006.

[5] H. Ishiguro et. al: "Building artificial humans to understand humans", Journal of Artifical Organs. Vol. 10(3), pp. 133-142, 2007.

[6] K. Kaneko et. al: "Cybernetic Human HRP-4C", Proc. of the 9th IEEE-RAS International Conference on Humanoid Robots, pp. 7-14, 2009.

[7] A. Burton: " Dolphins, dogs, and robot seals for the treatment of neurological disease" , The Lancet Neurology, Vol. 12, Issue 9, pp. 851 - 852, 2013.

[8] N. Endo et al.: "Development of Whole-body Emotional Expression Humanoid Robot for ADL-assistive RT services," Journal of Robotics and Mechatronics, Vol. 23, No. 6, pp. 969-977, 2011.

[9] T. Kishi et. al: "Development of Expressive Robotic Head for Bipedal Humanoid Robot," Proc. of the 2012 IEEE/RSJ International Conference on Intelligent Robots and Systems, pp. 4584-4589, 2012.

[10] S. Cosentino et. al: "Human-humanoid robot social interaction: Laughter", Proc. of the 2013 IEEE International Conference on Robotics and Biomimetics, 2013.

[11] K. Hayashi et. al: "Manzai robot", Journal of RSJ, Vol. 25, No. 3, pp. 381-389, 2007.

[12] "Manzai duo by Zenjiro and Papero" http://robot.watch.impress.co.jp/docs/news/20091022_323741.html.

[13] "Manzai duo by ii-1 and ii-2 in Konan universiy" http://www.robonable.jp/news/2012/01/konan-0117.html.

[14] J. M. Suls: "A two-stage model for the appreciation of jokes and cartoons: an information-processing analysis", Goldstein and McGhee,chapter 5,pp. 81-100, 1972.

[15] Y. Kimura: "Laugh as a science", Shin-yo-sha, 2010.

[16] H. Iyama: "Equation of laugh", Kagaku-dojin, 2007.

[17] I. tanaka: "Manners that member of society should know", Litto music, 2012.

[18] A. Nakamura: "Sence of laugh", Iwanami, 2002.

[19] Broadcaster seminor by Asai-kikaku: "Pro teaches the skill of laugh", Kodansha, 2006.

[20] K. Mizuno: "Skill to make people laugh", OS publisher, 2003.

[21] Ganso bakusho king: "How to do Manzai ",Litto music, 2008.

[22] Y. Tatsumoto et. al: "The positive laugh increase with the other's presence?", book of Kansai Fukushi University, 2006.

[23] McNair et. al: "Profile of Mood States (POMS)", 1989. 